\title{
An integration centric approach for the coordination of distributed software development projects
}

\author{
Lars Taxén
}

\section{Linköping University Post Print}

\section{Tweet}

N.B.: When citing this work, cite the original article.

Original Publication:

Lars Taxén, An integration centric approach for the coordination of distributed software development projects, 2006, Information and Software Technology, (48), 9, 767-780.

http://dx.doi.org/10.1016/j.infsof.2006.01.007

Copyright: Elsevier

http://www.elsevier.com/

Postprint available at: Linköping University Electronic Press

http://urn.kb.se/resolve?urn=urn:nbn:se:liu:diva-50135 


\title{
An Integrated Centric Approach for the Coordination of Distributed SW-projects
}

\author{
Lars Taxén \\ Campus Norrköping, Linköping University \\ Department of Science and Technology \\ Norrköping, Sweden \\ Postal address: Rundan 91, 14645 Tullinge, Sweden, Phone: +46 730977864 \\ \{lars.taxen@telia.com\}
}

\begin{abstract}
This paper presents an approach for Distributed Software Development (DSD) that is based on two fundaments. The first one is an integration centric engineering process, which aims at managing technical and social dependencies in DSD projects. The second fundament is a strategy for operationalizing the coordination of the engineering process. The purpose of this strategy is to provide global information system support for coordination and, simultaneously achieve a shared meaning about what should be coordinated and how. The approach has been successfully used at Ericsson, a major supplier of telecommunication systems worldwide. We discuss the effects of applying the approach in the coordination of extraordinary complex projects developing nodes in the $3^{\text {rd }}$ generation of mobile systems. Although many obstacles have to be addressed, the results show that the approach is a viable way to manage DSD during very demanding circumstances.
\end{abstract}

Keywords: distributed SW development, integration centric engineering, coordination, shared meaning, flexible IS/ IT support, telecom systems

\section{Introduction}

The interest in distributed software development ${ }^{1}$ (DSD) has increased due to factors such as reduced costs, the access to well-educated labor pools, the possibility of 24 hour development, global presence and proximity to customers (e.g. [6], [9], [12], [16], [17], [20], [26], [28], [29], [31]). The distribution, which may take place inside or across organizations, does not necessarily have to be global. However, many challenges already present in centralized SW development are aggravated by the distribution. At the core of these challenges lies the issue of coordination. "While there is no single cause of the software crisis, a major contributor is the problem of coordinating activities while developing large software systems." ([21], p. 69).

Some of the challenges that need increased attention in DSD are:

\section{Architectural design}

The architecture of the SW system should be designed in such a way that DSD is facilitated. It should be easy to identify development tasks that with low interaction. Furthermore, the architecture should be transparent in the sense that it can be easily communicated across the entire project [6], [28].

\footnotetext{
${ }^{1}$ This type of development has also been named Global Software Development [9] and Offshore development [31].
} 


\section{Software Engineering Process}

By this, we mean total set of software engineering activities needed to transform user requirements into software [19]. DSD makes the management of dependencies between these activities more difficult.

\section{Software Development Model}

DSD implies that the software development model must be carefully chosen. Sakthivel [31] has shown that there is a complex relationship between the potential for distribution and the type of development process (spiral, waterfall, Rapid Application Development, Agile Development Method, etc.).

\section{Project management}

The distribution of the development task brings about more demanding requirements on project management. When people cannot meet face to face, the burden of coordination and communication increases. The geographical separation means that effort estimations, project planning and control become more difficult. The need for a common understanding of project goals, plans and progress increases in DSD. In addition, the management of issues like trust, responsibilities, commitments, incitements, etc., is aggravated in DSD.

\section{Multiculturalism}

DSD implies an increased attention to cultural differences. A subtle balance must be struck between enforcing mandatory regulations imposed by coordination and local autonomy concerning development methods, support tools, etc. Going to either extreme will lead to problems. Enforcing a common development process on all sites will most likely arouse resistance and cause conflicts [14]. On the other hand, allowing full freedom for each site to control the development will make coordination across sites impossible.

\section{IS / IT support}

DSD puts higher requirements on the IS / IT support. The infrastructure in distant sites may be inadequate, which may cause problems with information system (IS) performance and stability. In addition, there is a need for a common project repository where requirements, engineering change orders, system builds, etc., can be globally available. This means that the IS architectures must be carefully designed with respect to what roles ISs should have and how they should interact.

In this paper, we will discuss how Ericsson, a major supplier of telecommunication systems worldwide, is facing the challenges associated with DSD in their development practice. The ensemble of telecommunication systems has been called the world's largest machine. It consists of networks of interacting nodes, each of which performs some kind of utility in the network like keeping track of the position of a cellular phone, providing charging functions, supplying data about the phone owner, etc. (see Figure 1). 


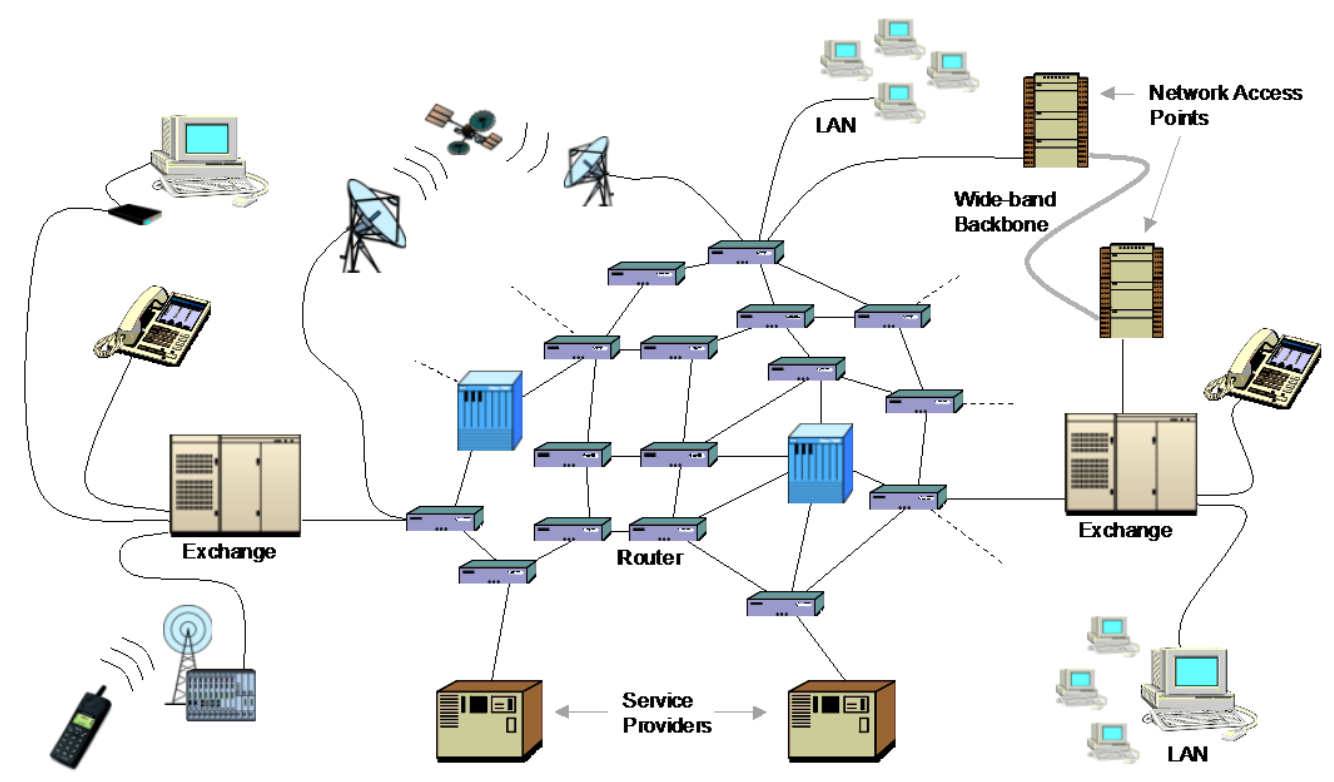

Figure 1: The principal structure of a telecommunication system

A telecom system is a truly complex system in several ways. The system is continuously evolving. Many different technologies are utilized such as radio, software, hardware, optical, mechanical, etc. There are very strict requirements on real-time access and system downtime. Furthermore, modern communication standards such as GSM (Global System for Mobile Communications) must be compliant with older ones.

In the telecommunications market there is a fierce competition among systems providers like Ericsson, Nokia and others. Moreover, this market is changing rapidly. Therefore, the suppliers have to be more reactive and flexible to the market needs. This in turn prompts frequent re-organizations, including company outsourcing and new partnership constellations.

In addition to these circumstances, the development task is inherently complex. The sheer size of the task is enormous. A project developing nodes in the $3^{\text {rd }}$ generation of mobile systems may take more than a year to execute and involve several thousand actors all over the world. The number of software code lines in some nodes may be in the order of millions. During the development, the outcomes of several hundreds of development steps must be coordinated, verified and integrated in a precise and timely manner. Furthermore, since there are a number of different technologies involved, very heterogeneous skills are needed.

The development is in general carried out at many different sites worldwide. These sites usually have some autonomy to structure their own way of working. As a result, the coordination of such projects must deal with a multitude of technical, market related and organizational interdependencies. Most often, this requires mutual adjustment across many types of both technical and organizational boundaries [1].

In summary, the development of a telecom system can be seen as a paradigmatic example of the challenges involved in DSD. The approach Ericsson has taken to address these challenges is based on two fundaments. The first one is an integration centric engineering process, which aims at managing technical and social dependencies in DSD projects. The second fundament is a strategy for operationalizing the 
coordination of the engineering process. The purpose of this strategy is to provide global IS support for coordination and, simultaneously achieve a shared meaning about what should be coordinated and how. In this paper, we will refer to the Ericsson way as the ICD (Integration Centric Development) approach.

The paper is organized as follows: In the next section, we give a brief account of the research design. In Section 3.1, we describe the engineering process. The core of this process is a construct called the "anatomy", which is an illustration - preferably on one page - of the functional dependencies in the system. The anatomy is the basis for building the total functionality of the SW-system is in steps - increments - that are consecutively verified and integrated from basic functionality to an operational system. The gist of process is to identify and manage critical dependencies in the development task, regardless of whether these are of a technical or social nature. Theoretical and practical aspects of the anatomy driven engineering process are treated in [23] and [35].

In Section 3.2 we outline how the engineering process is coordinated. This concerns various management activates such as project management, requirement management, engineering change order management, baseline and milestone management, test management, system build management, etc. The central idea is that actors involved in these management tasks together define how these phenomena should be apprehended and how the corresponding IS / IT support shall be implemented. In the following section we report on some effects from applying the approach in the Ericsson development practice. Finally, we discuss the results and draw some conclusions.

The paper is limited to the engineering and coordinating aspects of DSD. This means that we do not discuss the software development model. Moreover, even if we focus on SW development in this paper, the ICD approach is equally applicable if some functionality is provided by hardware.

\section{Research design}

The research results are derived form mainly two sources. The first source is experiences from the author's professional work at Ericsson. This concerns both theoretical and practical result achieved between roughly 1990 and 2003 [33]. The second source is a study of the use of the anatomy at one development unit at Ericsson, reported in [23]. The data sources are interviews, Ericsson internal documents, meeting notes, etc. (for details, see [33] and [23]). Thus, the empirical data is a mixture of personal experiences from many projects and a deeper study of one particular project.

In general, the research can be characterized as exploratory in nature and based on longitudinal case studies. The use of qualitative methods such as case studies is appropriate in studying human action in real life situations, especially those ones in which practice precedes theory[37]. Moreover, the research can, at least in part, be classified as action research [5] since the author has been actively promoting the IS / IT support for the ICD approach at Ericsson.

\section{The Integration Centric approach}

In this section, we will describe the two fundaments of the ICD approach. In Section 3.1 we outline the engineering process and in Section 3.2 the strategy for operationalizing the coordination of the engineering process. 


\subsection{The engineering process}

The engineering process is based on a construct called the "anatomy". The anatomy is an illustration, which shows functional dependencies in the system from start-up to an operational system ([3], [23], [35]). The central idea behind using the anatomy in system development is to design and test the system in the same order as it "comes alive". In order to achieve this, the engineering process is executed in three steps: anatomy definition, increment planning and integration planning. These steps are not sharply separated; rather they should be seen as different foci in the coordination of the development task. In the following sections, we will describe the principles of the engineering process using a simplified example from the Ericsson practice: the development of a processor in a telecom system.

\subsubsection{Anatomy Definition}

The purpose of the anatomy definition step is to achieve a shared meaning about how the system works in terms of functional dependencies. In Figure 2, the anatomy of the processor is shown. It is outside the scope of this paper to describe the working of the processor in detail. However, the name designations should indicate the character of the functions.

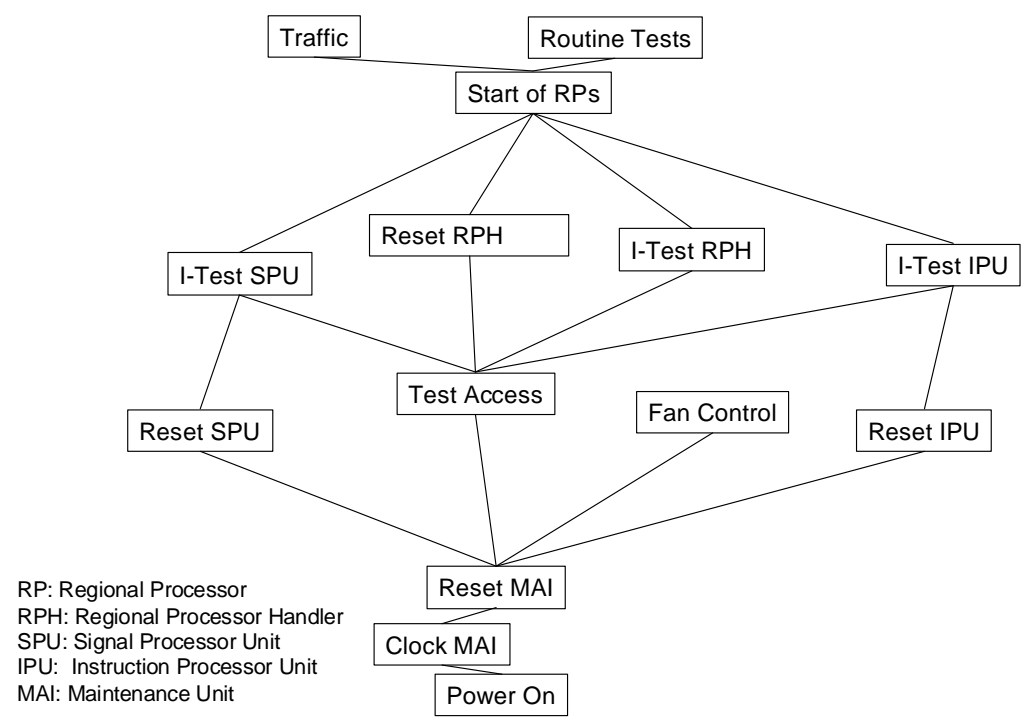

Figure 2: The anatomy of a processor in a telecom system

The anatomy is created in several meetings where the mindset should be: "if you 'power-on' what happen then and then." This question is repeated until you reach the end functionality. Thus, the approach is in essence a bottom-up process rather than top-down [3]. When deciding which functions to include, the focus should be on integration and testability since this will be used to plan and monitor the project.

It can be noted that the anatomy shown in Figure 2, is to a certain extent arbitrary. Other functionalities might have been included and the level of detail is more or less arbitrary. This indicates that the anatomy is, as indeed any other model, something that the actors must agree upon. Therefore, it usually takes several meeting before a working consensus is achieved. 


\subsubsection{Increment planning}

In the second step, the implementation of the system is defined. The functions are grouped into integration steps - increments - in such a way that the resulting functionality after each added increment can be verified. Thus, the dependencies in focus in this step are increment dependencies. The intention is to parallelize design and testing as much as possible. The increment plan describes in what order increments need to be completed to ensure smooth progress. The structure of the plan is determined by a number of circumstances such as available resources, customer feedback, complicated or simple functions, geographical proximity between resources, functions that can be tested jointly, etc. [3]. In Figure 3, a possible increment plan of the processor is shown.

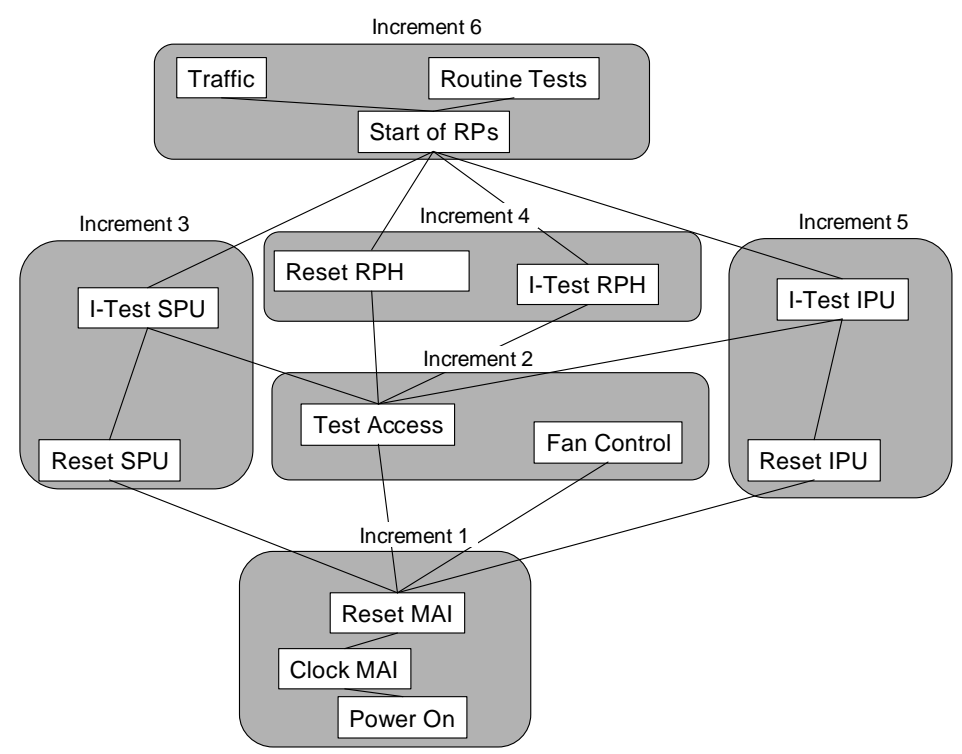

Figure 3: Increment plan of the processor.

\subsubsection{Integration planning}

In the third step, the purpose is to divide the work between subprojects and establish a shared commitment about what is delivered, from whom and when. This means that resources are assigned and dates for deliveries of the increments are negotiated. For each increment, traditional time and resource plans are made as well. The integration plan focuses on the dependencies between subprojects. It clearly shows the impact of delaying a certain delivery. Thus, it provides early warnings of delays, which give the project management time to take corrective actions. During the project, the integration plan is used as an instrument for controlling the progress of the project. The state of each increment is visualized by traffic-light cues such as Green - On Plan, Yellow - Warning, Red - Off Track, etc. 
In Figure 4, an integration plan of the processor is shown.

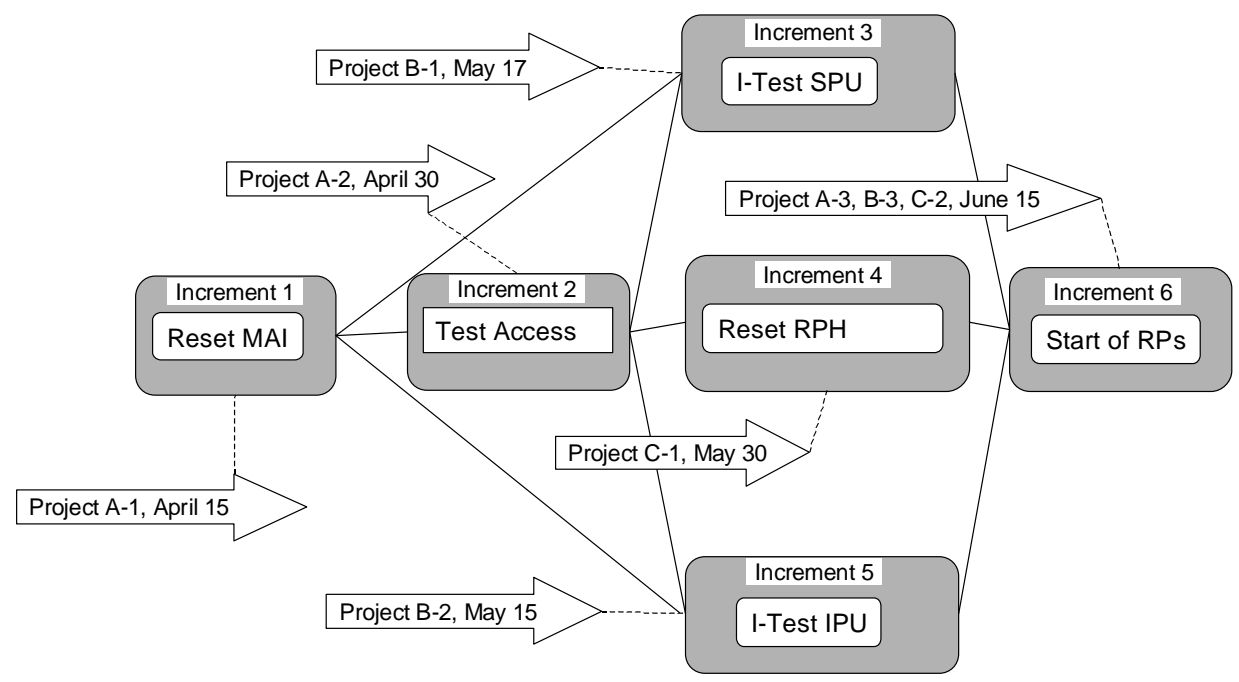

Figure 4: Integration plan of the processor

It can be seen that the increments are assigned to various subprojects depending on specific competences needed. For example, both increments 3 and 5 concern testing. Those increments are assigned to subprojects B-1 and B-2, indicting that both subprojects are run within sites that are knowledgeable in testing.

\subsection{Operationalizing coordination}

Co-ordination is a nebulous concept that has been defined in various ways (e.g. [22], [24], [27]). In the ICD approach, the definition of coordination departs from the definition given by Malone \& Crowston:

"Co-ordination is managing dependencies between activities" ([24], p. 90)

In order to operationalize this definition Taxén has suggested regarding coordination from a workpractice point of view ([33]). In a workpractice, actors come together in order to produce a certain result that other actors need ([15], [32]). Such a workpractice may be, for example, a development practice at Ericsson. In this practice, actors are performing various tasks. Some of these tasks have an explicit goal of coordinating the development. By regarding the workpractice from a coordination point of view, we can emphasize only those phenomena that are relevant for coordination. We will refer to this perspective of the workpractice as the coordination domain. This means that a certain item, say a requirement, will be apprehended differently depending on the perspective of the workpractice. From a development point of view, the understanding of the content of the requirement is in focus. From a coordination point of view, its status, revision and relation to other items are in focus.

It is outside the scope of this paper to give a detailed account for this line of reasoning (see [33] and [34]). The gist of the reasoning is that the actors in the coordination domain have to construct the domain in order to operationalize coordination. In order to do so, they work with mainly two instruments: a context model and an IS. The context model shows what items the actors consider important for coordination 
and how these are related to each other (see e.g. Figure 6). By continually iterating between modifying the context model, implementing it in the IS and evaluating the result, coordination is gradually constructed in terms of significant items (displayed in the context model), IS support and a shared meaning among the actors about what constitutes coordination. We will call this procedure the Domain Construction Strategy [33]. The motivation behind this seemingly awkward procedure is that the problem of achieving a shared meaning has turned out to be a major obstacle in DSD (e.g. [6], [17], [26], [28], [29], [31]).

The construction of the coordination domain is carried out in three phases: elaboration, trust boosting and expansion (see Figure 5). In the first two phases, the focus is on establishing the coordination domain as a bridgehead in one project before expanding it to other projects in the third phase. This means that the gist of the strategy is the quick establishment a relatively stable core of shared meaning in a small group of actors, which is then propagated to other actors in an ongoing domain construction process.

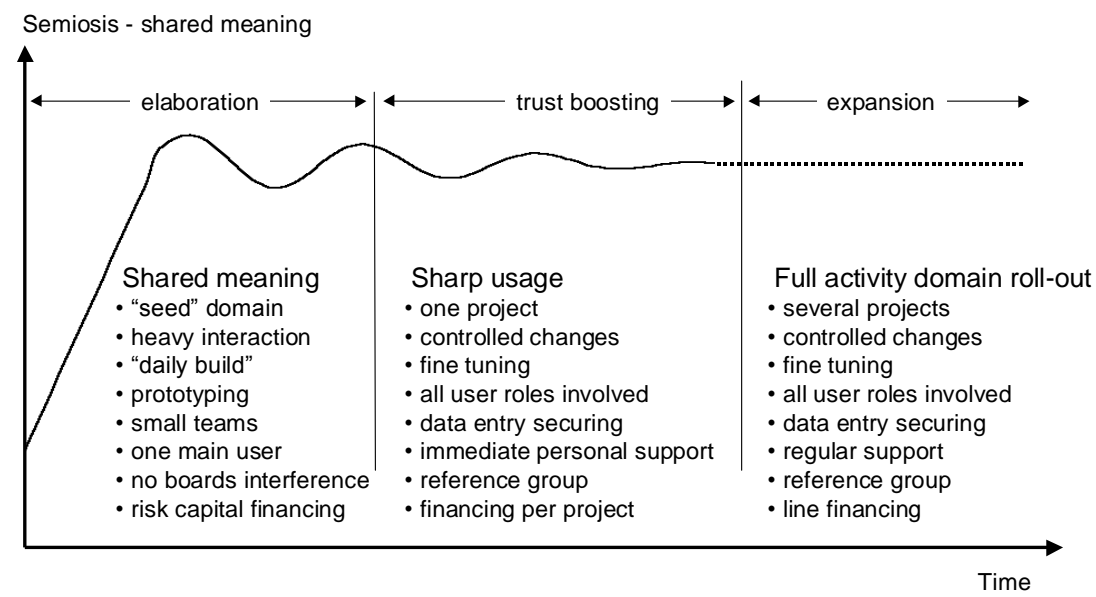

Figure 5. The domain construction strategy

\subsubsection{Elaboration}

In this phase, the initial construction of the domain is carried out. The main purpose is to achieve a tentative consensus about the content and structure of the domain. The work is carried out in a 'daily build' manner in close interaction among the actors. The work is financed on a risk capital basis. Detailed return on investment analysis is not required since the reliability of such analysis will be low. The following tasks are carried out in this phase:

- State the coordination requirements on an overall level, for example, "There shall be support for engineering change order management, requirement management (RM) and ICD based software development". These different areas within the coordination domain are called coordination areas.

- Define a "task force" for each coordination area. For example, for RM this force may consist of a project manager, a requirement manager and an IS specialist. 
- Define a first version of the context model is terms of relevant phenomena and how these are related to each other. Established methods may be used as a point of departure. Define attributes, cardinalities, revision stepping rules, state sets, etc. In Figure 3, an example from Ericsson of a context model is shown.

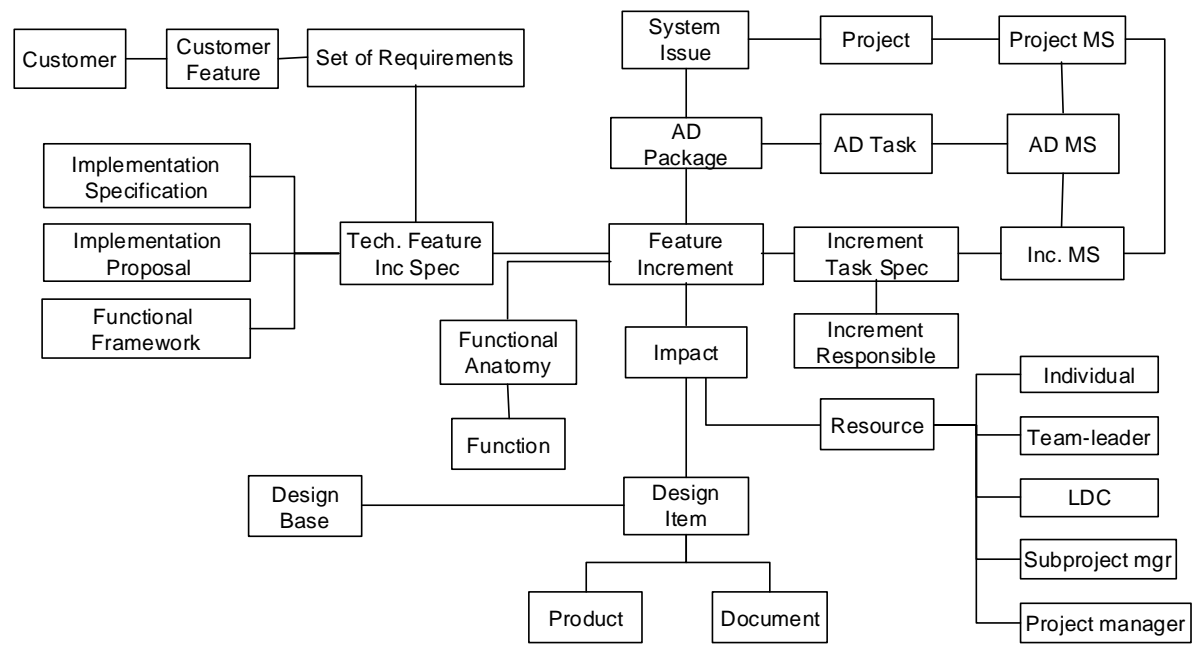

Figure 6: An example of context model in the Ericsson practice (1997).

- Implement the context model in the IS. Instantiate object of the types, for example, a number of requirements and requirement issuers, and relate them to each other. Create reports. Evaluate the information: What is missing? Is this correct? Etc. In Figure 7, an example of this kind of information, corresponding to the context model in Figure 6 is shown.

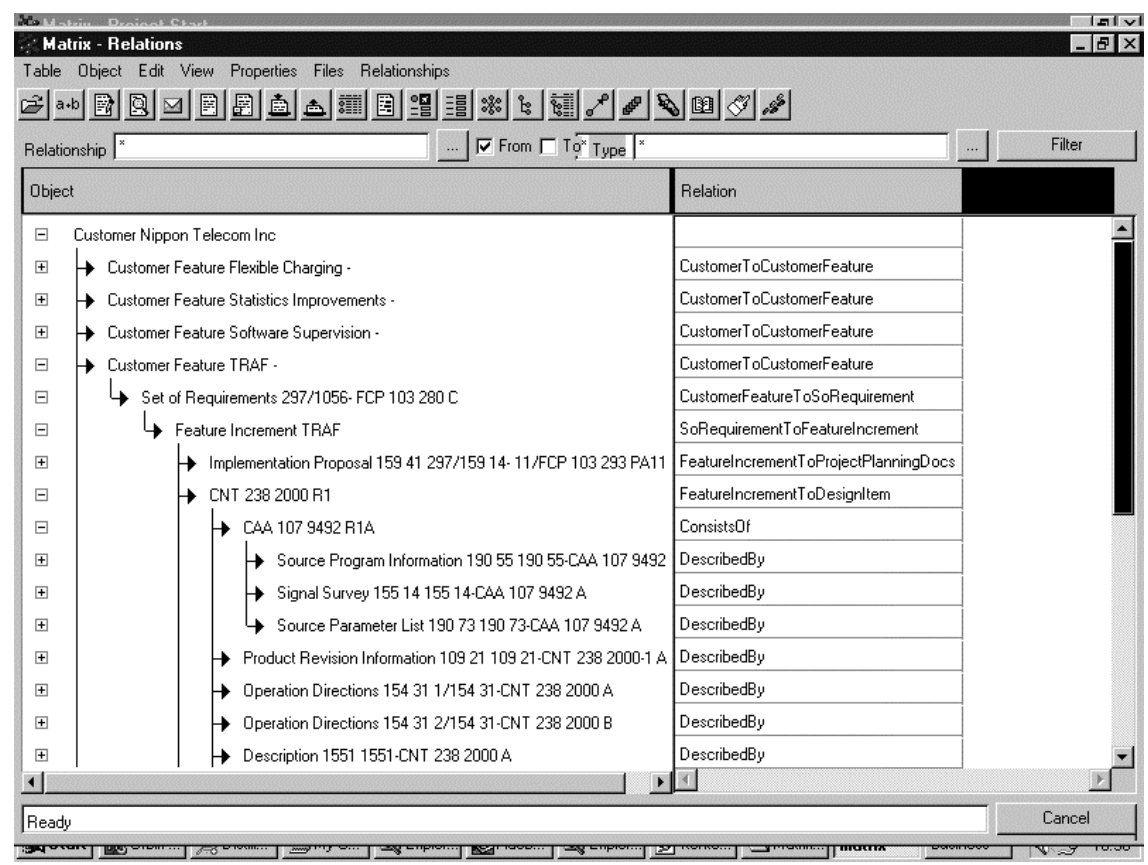

Figure 7: An example of requirements tracing from customer to system elements (1997) 
- Make changes to the context model and implement these anew. Continue in this manner until the actors agree that the constructed domain is useful.

\subsubsection{Trust boosting}

The purpose of this phase is to boost the trust about the feasibility of the domain as constructed in the elaboration phase. Key issues are getting all actors in the project to trust the data in the IS and make sure that the performance of the IS is acceptable at all units worldwide. This is done in one sharp project, that is, a project that develops a product for some client. The task force is still driving the construction. All user roles around the project are involved, and immediate, personalized support is provided. The development of the domain progresses by controlled changes and consists of fine tuning steps. No major reconstruction of the domain is allowed. Reference groups and steering boards are consulted and the financing is done on a project basis. The following tasks are carried out in this phase:

- Transfer data from previous sources into the IS. For example, requirements previously kept as text in requirement specification documents are translated into requirement objects, which can be individually managed and related to other items according to the context model.

- Set a date when the project shall start using the data in the IS as their primary source for planning and monitoring the project. The reason for this is that the data otherwise may be inconsistent.

- $\quad$ Take measures to make the actors use the IS, i.e. enter data into and retrieve data from the IS. This can be done by requiring that the only source for progress reports is the data in the IS.

- Keep a list of issues that need to be attended. Any such issue needs to be agreed upon by the task force before it is implemented in the IS.

\subsubsection{Expansion}

In this phase, several projects are involved. As in the trust-boosting phase, the construction is done by controlled changes, however now in a formalized way. The financing is done by the line organization in order to keep the domain intact between projects. The following tasks are carried out in this phase:

- Changes in the models must be agreed upon by a change control board before it is implemented in the IS. This means that an incoming issue is sent out to an analysis group where its impact is estimated in terms of cost and implementation effort. A formal decision to go ahead is taken and the issue is followed up until it is fully implemented.

- If the domain has to cooperate with other domains, a work must be initialized to coordinate these domains. When doing so, a balance must be struck between what is necessary to coordinate and what can be left to each individual domain to decide independently. 


\section{Results}

The ICD approach has been applied in the Ericsson practice for several years. In the development of the $3^{\text {rd }}$ generation of mobile systems the ICD approach was used in approximately 140 main projects and subprojects between 1999 and 2002 [33]. In Figure 8 , the integration plan of one of the most complex nodes in the $3 \mathrm{G}$ telecom system is shown. This node was developed by 27 subprojects distributed over $22 \mathrm{de}-$ velopment sites in altogether 18 countries.

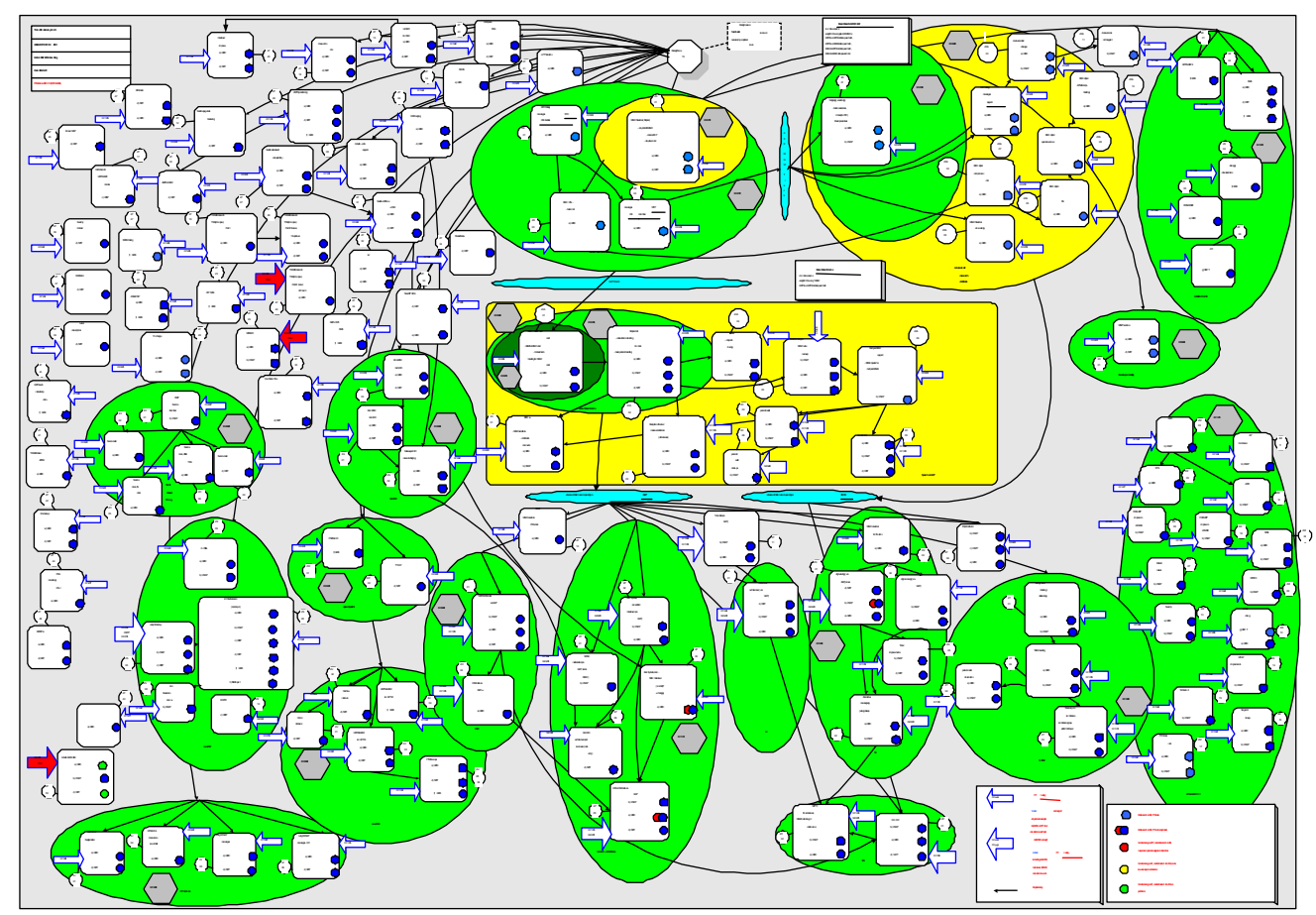

Figure 8: The integration plan of the Mobile Switching Centre node.

In Figure 9, the main elements in the integration plan are illustrated.

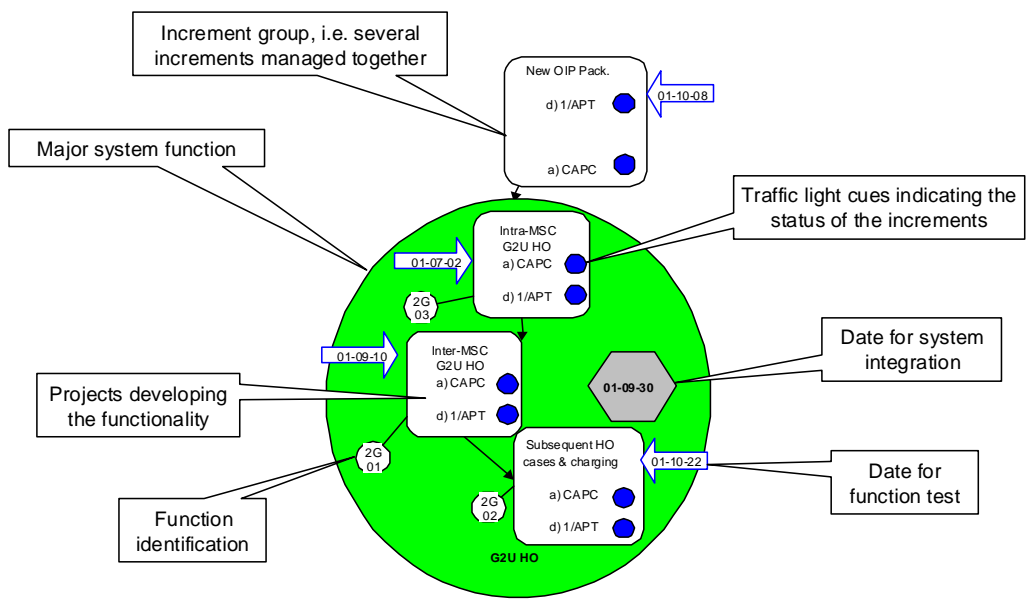

Figure 9: A detail of the integration plan in Figure 8. 
In the $3 \mathrm{G}$ development, two major coordination domains were constructed: the Sdomain situated in Stockholm, Sweden and the A-domain situated in Aachen, Germany. The purpose of these two domains was the same: to provide coordination support for the development projects. However, these sites developed different parts of the telecom system. The A-domain projects were developing SW parts only, while the Sdomain projects were developing both SW and HW parts. Furthermore, over the years these domains had evolved different ways of coordinating development.

Each domain was supported by two logically separated ISs built on the same platform, the Matrix PDM system from Matrix-One [25]. In essence, this means that there was no technical interaction between these systems. The main reason for choosing two separate ISs was that achieving consensus about a common way of coordinating the project was considered unfeasible in the time span available.

In Figure 10, a high-level view of the context models for the $\mathrm{S}$ domain is shown.

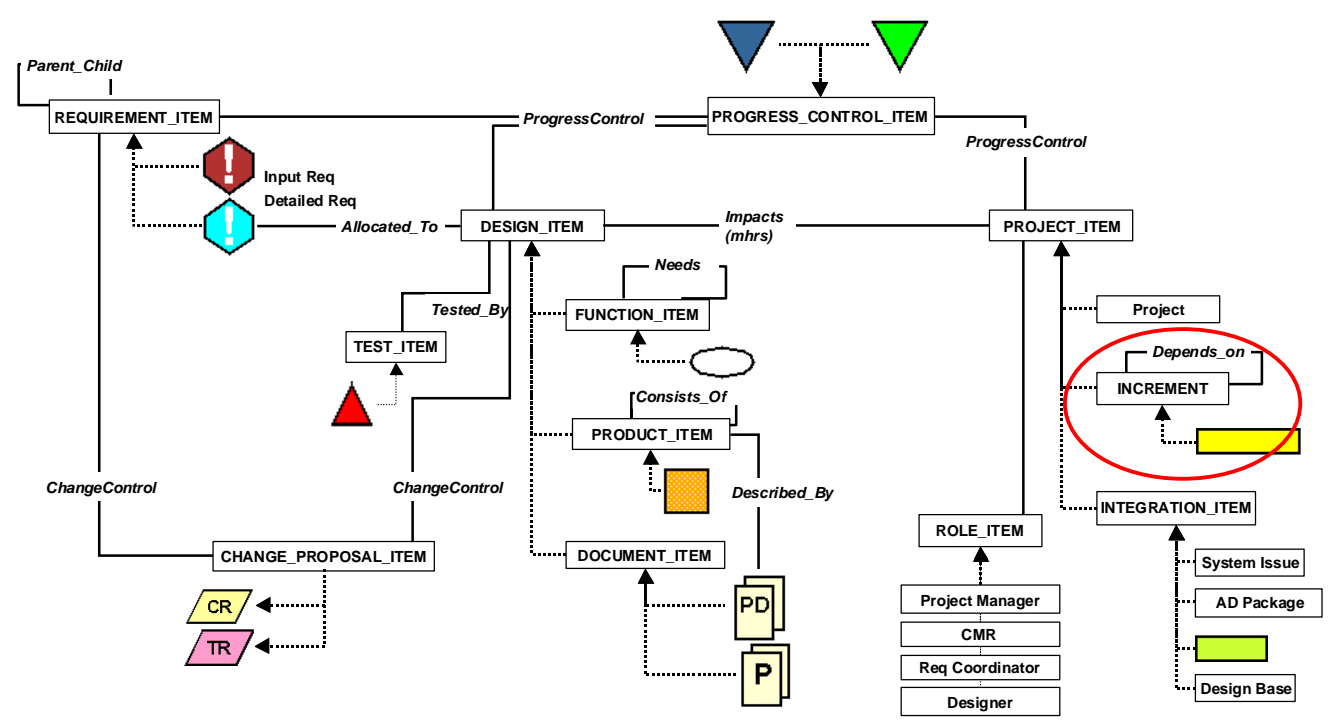

Figure 10: The S-domain context model (1999)

The elaboration phase of the S-domain occurred approximately between 1998 and 1999. During that period, the following coordination areas were made operational:

- Requirement management (REQUIREMENT_ITEM in Figure 10),

- Engineering Change Order management (CHANGE_PROPOSAL_ITEM),

- Baseline and milestone management (PROGRESS_CONTROL_ITEM),

- Test configuration management (TEST_ITEM),

- Support for the ICD approach (FUNCTION_ITEM, INCREMENT and INTERGRATION_ITEM),

- Product and document management for the needs of the project (PRODUCT_ITEM and DOCUMENT_ITEM). 
The work was mainly carried out by the author, another Ericsson employee and 1-2 consultants in close interaction with key users such as project managers, configuration managers, etc.

In Figure 11, the corresponding context model for the A domain is shown. The elaboration phase of the A-domain occurred approximately between the end of 1999 and mid 2000.

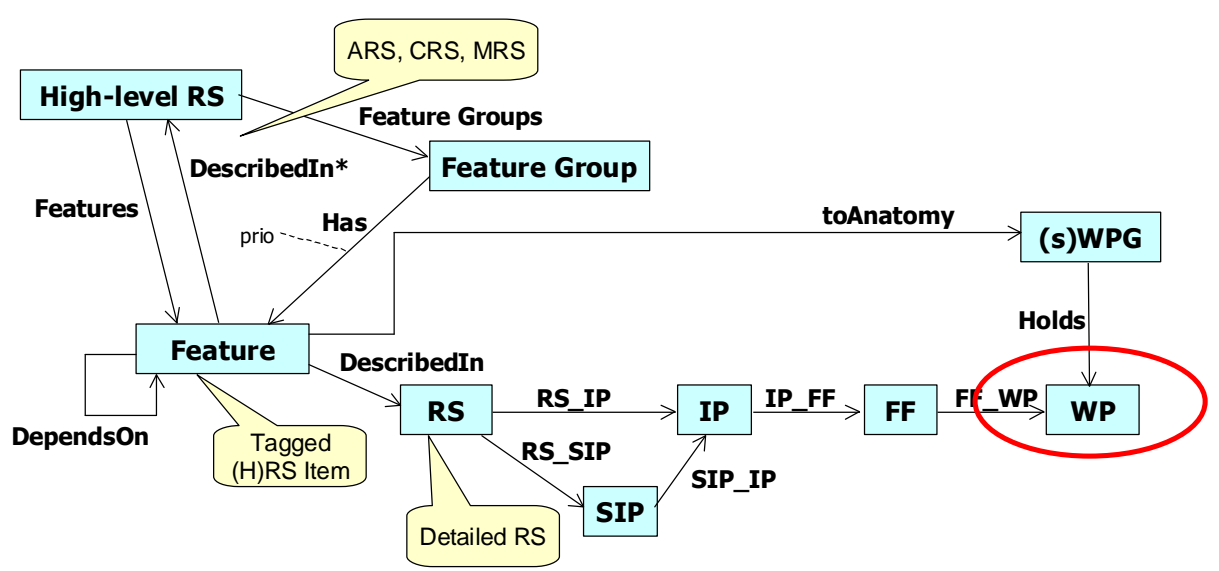

Figure 11: The A-domain context model (2000)

The items in the models signify phenomena that the actors in each domain have found relevant to coordinate. The nomenclature is mostly Ericsson specific. The most striking observation is that the context models are completely different. The only items in common are the encircled ones: "Increment" and "WP" (work package). A work package is essentially the same as an increment. However, not even the names were equal in both domains. The increments items differed in practically all aspects such as attributes, life cycle states, etc.

These observations support the assumption that it would have been very hard to reconcile the two domains from the outset. In order to achieve the necessary coordination support these domains had to be constructed independently of each other. The obvious drawback is that the coordination across the domains had to be done without IS support.

The ICD approach was in a sense a one-time shot at Ericsson. The specialized IS support and the application of Domain Construction Strategy in combination with the anatomy way of working were effective only between approximately 1999 and 2002 . After 2002, the coherent ICD approach began to disintegrate. The context model turned into a "Common Ericsson Model" maintained by a line organization. The close interaction between users and developer inherent in the Domain Construction Strategy was replaced by a conventional development strategy, in which the interaction between users and developer became more remote and formalized. This was partly due to an outsourcing of the development task to another organization. At the end of this study (2003), work began to consolidate the A and S domains into one, central domain for the entire Ericsson company. This means that the integration centric way of working is still prevalent at Ericsson, albeit in a fashion which in many respects is completely different from the ICD approach as described in this paper. 


\subsection{Effects}

In this section, we will give an account of the effects from applying the ICD approach in the $3 \mathrm{G}$ development. The effects are grouped under a number of effect categories, and the findings are corroborated with samples of quotations from various actors. These include project managers (PM), configuration managers (CM) and method \& tools support responsible actors (MT). In the quotations "I" stands for interviewer and "R" for Respondent. "Matrix", "database" and "tool" refers to the IS in the ICD approach. A detailed account of the effects is given in [33].

Taken as a whole, the effects have been profound. Some project managers claimed that the development of one of the most complex nodes, the so-called Mobile Switching Centre node (see Figure 8), would not have been possible without the ICD approach. This is captured in the following quotation:

"Especially for the execution part I think we would not have been able to run this project without the tool. I think if you simply look at the number of work packages, the number of products that we have delivered, the number of deliveries that we have had, if we would have had to maintain that manually, that would have been a sheer disaster. [...] we had some, only in my part of the project, some 200 work packages or work packages groups or whatever you want to call them, deliveries, on the average 2-5 subprojects within them 5-10 blocks being delivered, just keeping track of that [...] would have been a hell of a job." (PM4, A-domain).

Thus, the fundamental effect is that the ICD approach was a sine qua non for the $3 \mathrm{G}$ endeavour.

\subsubsection{Managing evolution and change}

This category refers to effects regarding the evolution of the coordination domain and changes. Two types of evolution of the coordination domain can be identified. The first one concerns the elaboration phase in the Domain Construction Strategy. This evolution can be characterized as a "daily build" where changes are made more or less on the fly during an ongoing project. The other type of evolution concerns a longterm evolution which is related to impacts from external changes, adding new coordination support, providing maintenance, etc.

\section{Daily builds}

In the elaboration phases between 1999 and 2002, around 200 changes were made in the A-domain and 500 changes in the S-domain. A necessary prerequisite for the daily build type of changes is that the implementation in the IS is extremely easy to change, which is the case with Matrix. The daily build has the drawback that the application may turn out to be a patch work which has to undergo major reconstruction. However, the experiences were that these problems could be mastered.

\section{Long-term evolution}

The long-term evolution of the domain should be done gradually and build on existing knowledge. It should be possible to adhere to known ways of working. One example of this is the Engineering Change Order process that evolved from the existing, document oriented way of working:

"Because that was the point with Matrix, that we should be able to take our process, which really wasn't that well documented at that time, and adapt it to the tool. And the 
tool should be able to do the job that we,... that if we wanted it to work in this way, then it should be possible to adapt the tool to that." (CM1, S-domain)

A gradual evolution of the coordination domain was made possible with the ICD approach:

"Well, the positive effects that we have, that is that we have an integrated project support system where we have tremendous possibilities to improve, continuously improve our operations." (PM2, S-domain).

This meant that the coordination domain could be constructed by attending one coordination area at a time. At the S-domain, requirement management and engineering change order management were prioritized. At the A-domain, on the other hand, work package integration management was top priority.

\section{Re-planning}

The ever increasing turbulence of the market in general and the $3 \mathrm{G}$ market in particular made re-planning a major issue in the projects. About 500 Engineering Change Orders had to be considered, which meant that the project, increment and integration plans had to be continuously updated. The ICD approach was the cornerstone in building up the capacity for re-planning. Without this, the complexity could not have been managed.

\subsubsection{Enhanced orientation}

"Orientation" refers to the ability of actors to orient themselves in the coordination domain. Some aspects of orientation are awareness of dependencies, focal changes and traceability.

\section{Dependencies}

The anatomy in the ICD approach proved to be a good instrument for signifying dependencies:

"And also based on the anatomy chart, which is also I think a very important mechanism, you see a lot of dependencies both time wise and product wise, etc. So you can fix things that need to be fixed first and fix problems that are at the end of the project so to say at a later stage. Of course that is also a key issue." (PM4, A-domain)

However, the anatomy captures only functional dependencies in the telecom system. In order to manage all the dependencies expressed in the context model, the Matrix IS was necessary:

"R: I think for the MSC [Mobile Switching Centre node] there is a clear need for the tool and I have met now a couple of people who have said: without the tool we would not have survived the projects. [...] I: Is that due to the complexity of the node itself? $\mathrm{R}$ : yes, the complexity of the node, the complexity of the dependencies, time pressure people have. If you visualize dependencies it is far easier to take decisions." (PM3, Adomain)

\section{Focal change}

Orientation in a complex situation is alleviated if the attention can be directed to various foci while simultaneously maintaining the interdependencies between them. The 
ICD approach made it possible to direct the attention to any foci inherent in the context model:

"R: You can look at different levels because of... how shall I say that.... you can look at it on a very overall level and you go down to specific as you want to up to document status." (MT4, A-domain)

\section{Traceability}

Traceability can be seen as a particular kind of dependency where the purpose is to follow a path of dependencies from, for example, requirements to customer deliveries. Again, the ICD approach enabled this:

"We have a good support for configuration management, our engineering change orders are in order, our baselines are in order, etc. In addition I think that we have the possibilities to manage requirements in a good way and make them obvious and we can achieve a very clear traceability all the way from customer requirements one might say." (PM2, S-domain)

\subsubsection{Clear separation of concerns}

The effects gathered under this heading are related to the separation of a complex situation into contexts, which are meaningful and comprehensible for the actors. For example, from the point of view of total project management, the attention is directed towards the status of each work package and the dependencies between them. On the other hand, from a single work package point of view, the focus is on the inner of the work package. The ability to move between these different levels proved to be beneficial:

"Of course there is also something that is maybe also a benefit of the tool is that we do have different levels of projects. And the tool can really provide support for various levels, [...]. It is one common database with everything in it. It's just a matter what kind of information you are interested in. You don't have to summarize all the data from lower levels into reports for higher levels, its all in the tool and you can ask some mechanism to load it, that is very valuable." (PM4, A-domain)

Another consequence is that the need for the total project management to engage in coordinating sub-projects has decreased:

"Yes, what is of course also the great benefit, and that is also the feedback we get from other subprojects, is that you have one common place where all the project area stored the information. It's very easy to look up certain things like PA1 [Product Area] needs the status of a WP [work package] from PA2 and it's simple to go to the tool and see what it is all connected to. It means that a lot of the coordination which previously went via the main project, now can go directly. It's closely tied to the work package concept of course. A lot of coordination is now happening on the level it should be and that's on the subprojects level and not via the main project any more." (PM4, A-domain)

\subsubsection{Clarifying responsibilities}

One effect of the ICD approach was that it became more difficult for actors to escape their responsibility by pointing in other directions:

"There was always a huge debate whether there is a problem in the build content list or not. People usually said... if you talk to development projects they always said we don't have a problem, it's him. I will never forget I was in a meeting where they were actual- 
ly pointing in a circle. So at the end of this meeting everybody said "It's not my problem, it must be somebody else!". So nobody in this meeting had a problem. Nobody could even think of having being even close to a problem. But at the end of the day the build process didn't work. So obviously somebody must have had a problem. And they said no, they cannot believe it. And without a proof that it is their problem they would not do anything about it. So they were not even willingly to improve. Now this tool makes it so damn visible that they have a problem... "(PM3, A-domain)

The enhancement of possibilities was enacted through a tedious learning process in which the actors together learned how different pieces of information were related:

"R: Before every role maintained a piece of information it was responsible for. But in the end all pieces put together, they should build an overall picture and what Matrix enables us to get, this full picture also to cross the border and see "aha this is information somebody else in another role thinks is connected to this one" that is a complete picture of the overall view and not just the limited view the person is responsible for. That is the main benefit I think." (MT3, A-domain)

\subsubsection{Improved quality}

There are some indications that the ICD approach contributes to an improved quality. For example, it became easier to locate the sources of errors:

"The only thing I can say is we are now able to focus on the problems [...]. [The concept] makes it much easier to see where the problems are. In the good old days it was one big blob so to say. If there was a problem in there you had to really dive in and find out what the problem is. Now with the work packages it is pretty easy, or easy, relatively easy to pin-point where the problem is and then you can fix that part." (PM4, Adomain)

Another important aspect of quality is to maintain consistent and reliable data in the IS:

"R: But the next point is the most important one I think [having one information system for managing items rather then several], that is the one, that is the argument that has convinced the project managers and the head of the project office and the different people that took to use the tool, to have a consistent set of data."(MT3, A-domain)

In addition, the ICD approach improved the data consistency:

"R: I think that the Excel spread sheets they were maintained before in different places. They were always inconsistent. The technical coordinator has decided that an IP [Implementation Proposal] was removed but then in the others it still appeared. They had different titles and always, they had never the same revision.[...]. So I think the quality of the information has become much better." (MT3, A-domain)

\subsubsection{Managing the transition process}

A key issue in the diffusion of the ICD approach is to manage the transition from the established way of working to the new one. This process needs to be driven by devoted "entrepreneurs", that is, people with a strong belief in an idea or innovation, in alliance with influential key actors. These key actors need not be top-management. In the A-domain, the author formed this alliance with the first project manager to use Matrix in a sharp project.

The contradiction between tradition and transcendence is well-known in the literature. For example, Ehn expressed this in the following way: 
"[If] I should single out one aspect that to me seems to be the most crucial to design philosophy, it must be [...] the dialectics of tradition and transcendence in design and use." ([11], p. 127)

The most salient expression for this dialectic concerned the use of Matrix instead of conventional documents. This concerned, for example the management of individual requirements instead of requirement specification documents. Previously, the document was the coordination item that was updated, put under revision control, etc. Now, that document turned into a report generated from the new coordination items the individual requirements. The transition was hard on many occasions. Some persons bluntly refused to use Matrix unless it could be proven that the traditional documents could be recreated from the IS.

\section{Participation and feedback}

The first A-domain project experienced severe problems at the Australian site with Matrix in the beginning. Both the reliability and performance of the IS was unacceptable (see Section 4.1.8). The main project in Stockholm did not pay enough attention to this, which caused a lot of frustration:

"Yeah I hope there are some positives to be taken...it is only negative because the positive side is not coming through. It's kind of like saying that this doesn't work, and then someone says 'OK here is the patch that fixes it', then there is a big smile. The unhappiness here is that it doesn't work but the fix doesn't come through. And that's where the frustration is, it's not so much that tool is slow, it's the fact that peoples kept saying it's slow for so long. It's not so much that the tool couldn't do something, it's that people kept saying it couldn't do it for so long. And it just seems to take such a long time for things to happen. And we are very detached from the central expertise up there in Sweden. But I think people can see a lot of positives happening if the feedback is improved." (MT2, A-domain)

These problems were technically solved later on. However, the problems could have been much alleviated if measures had been taken early to counteract feelings of being left alone and disregarded.

\section{Trusting the data in the IS}

A major difficulty in all coordination domains was to convince the actors of entering data into Matrix. There were various reasons for this: lack of support resources, resistance to change established ways of working, poor performance of early versions of Matrix at distant sites, problems to understand the user interface, etc. However, a main reason was that the actors did not understand why they had to enter the data. From their point of view, entering data in a cumbersome IS was just an extra burden.

One strategy to advance the entering of data was to expose the responsible persons in public for not having done their job:

"So taking the database as input for the discussions at the project meetings, that was the main driver for the subproject manager to put the information there. If there were reports were... all the Work Packages were red just because they didn't enter the information, and this is presented in a project management meeting, then of course the next time they had updated it." (MT3, A-domain)

The key issue concerning data reliability is to promote the quality of the data to the level where the actors feel they can trust it. This can be achieved by creating a chain 
of dependencies among the actors in such a way that if someone fails to enter the data, the others will suffer:

"I: Did that [the entering of data] improve much when this decision to use the database for reports was taken? R: Yes, it was used by several roles we have in the project, and I think each area, for example the technical coordinator he has used Matrix, and the test has used Matrix. And as soon as different roles take the reports as input for their activities you must trust them. That is the driver to motivate all the people to enter the information into the tool." (MT3, A-domain)

\subsubsection{Constructing shared meaning}

Achieving shared meaning is by no means an easy task. In [33] an illustrative example is related. A group of eight actors were discussing the meaning of one item (a requirement type) in the context model without coming to a conclusion after two hours. Considering that the entire context model may contain several hundreds of elements (types, relations, attributes, state sets, access rights, etc.), it is quite easy to imagine the difficulties of a larger group of actors (say hundreds) to agree on the meaning of all the elements in the context model. In addition to that, the domain will change due to external circumstances, new insights, new coordination situation, etc.

The intended effect from the Domain Construction Strategy is that shared meaning emerges in the construction of the domain. There are several indications that this in fact happened, for example:

"I think that the traceability we used heavily. For we didn't have one object type just being on its own, it was always to show impacts of relationships to other, and... what this traceability...when we talk about relationships in Matrix, then there were different roles being responsible for the part and that together, all the different roles together, they build the overall picture then." (MT3, A-domain)

\subsubsection{Enabling IS / IT support}

In this section we will give an account for effects concerning the IS / IT support in the ICD approach. The key enabler of this support was the ease by which the implementation in Matrix could be changed. This allowed the Domain Construction Strategy to be fully employed since there is an ongoing iteration between adjusting the context model and implementing it in Matrix. The basic functionality of Matrix, such as implementation of the context model "on the fly" without re-compilation, logging all events, defining user roles and access rights, security checks, etc. turned out to be quite acceptable.

\section{Performance and stability}

In each of the $\mathrm{A}$ and $\mathrm{S}$ domains, a Matrix server was installed. This was accessed from the development sites globally. No attempt was made to set up a replicated installation in which the databases could be placed closer to the development sites. This was considered too expensive and awkward to manage. However, it turned out that the Ericsson intra-net was not sufficient for the server - client architecture chosen. Severe performance problems were experienced at Australia and other sites as well. This state of affairs threatened the continued usage of the tool on several occasions:

"Well, in principle all the PA's [Product Area responsible], or the subprojects, were enthusiastic using the concept because it had benefits for them as well. They could see the progress in other areas on which they were depending. However we had quite a lot of 
issues with performance. It simply was very slow outside of EED [the central organizational unit in the A-domain]. This was a major issue. People complained that just updating one attribute took them 2 hours or so. That simply takes too long. This came from several sites, Croatia, Australia, Dallas, wherever." (PM4, A-domain)

Moreover, the stability of the system was poor in the beginning. This situation was drastically improved with the introduction of a servlet-based web-client. Thus, a major lesson is that issues like performance and stability should be up front. Furthermore, the continued evolution of applications must not jeopardize the performance.

\section{User acceptance}

The user acceptance of Matrix has in general been low. The user interface was considered hard to understand. Only with the advent of the servlet-based web-client did this improve. In this client most of the particulars of Matrix was hidden.

\section{Reports}

Somwhat unexpectedly, it turned out that a key success factor in the deployment of the ICD approach was the availability of various report generators. In Figure 12 an example of such a report is given:

\begin{tabular}{|c|c|c|c|c|c|c|c|}
\hline XYर eMatix HTML Query - Nets & pe & +2 & 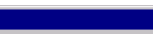 & 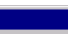 & 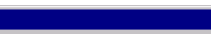 & -1 回 & \\
\hline & & & & & & & \\
\hline \multirow{2}{*}{\multicolumn{5}{|c|}{$\begin{array}{l}\text { ADM-Workpackage Relationships } \\
\text { Created 2000-08-04 } 16.34 .17 \text { by Anita Behle }\end{array}$}} & \multirow{2}{*}{\multicolumn{3}{|c|}{ eMatrix HTML Table Writer }} \\
\hline & & & & & & & \\
\hline Object & Slogan & Dependent WPs & $\begin{array}{l}\text { Connected } \\
\text { Blocks }\end{array}$ & swPG & IPs & Owner & \\
\hline Work Package, B08a/02, & BASE - AD4 & $\begin{array}{l}\text { B08a/03, B08b/01, } \\
\text { F03a/01, C06f/01 }\end{array}$ & BEACC & B08a & $\begin{array}{l}189 / 159 \\
28\end{array}$ & SP- Harvey. EED & \\
\hline Work Package, B08a/03, & BASE - ADS & $\begin{array}{l}\text { ContainerWP - } \\
\text { LSV10 } \\
\text { EED-Harvey, } \\
\text { B08b/01, F03a/01 }\end{array}$ & BEACC & B08a & $189 / 159$ 41-2/FCPW 101 & SP- Harvey. EED & \\
\hline Work Package, B08c/02, & BT - AD4 & $\begin{array}{l}\text { B08c/03, B08b/01, } \\
\text { F03a/01 }\end{array}$ & $\begin{array}{l}\text { BTAAL2, BTCM, } \\
\text { BTDA }\end{array}$ & B08c & $\begin{array}{l}187 / 159 \\
28\end{array}$ & SP- Harvey: EED & \\
\hline Work Package, B08c/03, & BT - ADS & $\begin{array}{l}\text { B08c/04, B08b/01, } \\
\text { F03a/01 }\end{array}$ & BTA_AL2, BTCM & B08c & $\begin{array}{l}187 / 159 \\
28\end{array}$ & SP- Harvey. EED & \\
\hline Work Package, B08d/01, & $\mathrm{BR}-\mathrm{AD} 1$ & B08d/02 & TRAREB & B08d & $\begin{array}{l}67 / 159 \text { 41-2/FCPW } 101 \\
28,121 / 15941-2 / \mathrm{FCPWW} \\
10128\end{array}$ & SP. Harvey. EED & \\
\hline Work Package, B08d/02, & $B R-A D 3$ & $\mathrm{~B} 08 \mathrm{~d} / 03$ & $\begin{array}{l}\text { ANDP, BADA, } \\
\text { DA, RA, RODA }\end{array}$ & B08d & $\begin{array}{l}67 / 159 \text { 41-2/FCPW } 101 \\
28,121 / 15941-2 / \mathrm{FCPWW} \\
10128\end{array}$ & SP- Harvey. EED & \\
\hline Work Package, B08d/03, & BR-AD4 & $\begin{array}{l}\text { B08d/04, B08b/01, } \\
\text { F03a/01 }\end{array}$ & $\begin{array}{l}\text { ANFH, TRACO, } \\
\text { TRARE, } \\
\text { TRACOB }\end{array}$ & B08d & $\begin{array}{l}67 / 15991-2 / \mathrm{FCPW} 101 \\
28,121 / 15941-2 / \mathrm{FCPWW} \\
10128\end{array}$ & SP- Harvey. EED & \\
\hline Work Package, B08d/04, & BR - AD5 & $\begin{array}{l}\text { B08d/05, B08b/01, } \\
\text { F03a/01 }\end{array}$ & TRAREB & B08d & $\begin{array}{l}67 / 159 \text { 41-2/FCPW } 101 \\
28,121 / 15941-2 / \mathrm{FCPWW} \\
10128\end{array}$ & SP. Harvey. EED & \\
\hline Work Package, C04a/02, & \begin{tabular}{|l|} 
SSF Charging \\
Adaptation to OIP \\
and PCDSE. Rest of \\
TR $\triangle M$ M dantatinn
\end{tabular} & $\mathrm{C} 04 \mathrm{a} / 01$ & SHCHM & $\mathrm{CO4a}$ & $\begin{array}{l}\text { 131/159 41-2/FCPW } 101 \\
28,185 / 15941-2 / \mathrm{FCPW} \\
10128\end{array}$ & SP- CHS: LMF & - \\
\hline \multicolumn{8}{|c|}{$\begin{array}{l}\text { TR } \Delta M \Delta \Delta \text { dantatinn } \\
\text { Document: Done }\end{array}$} \\
\hline
\end{tabular}

Figure 12: A web-based report showing information related to work packages (increments).

Another report generator called the Relation Viewer could display relational information in a matrix form similar to the dependency matrices defined by Eppinger et al. [13]. An example of is given in Figure 13: 
Figure 13: A web-based relational view of an anatomy.

These reports provided a good overview of communicating the status of the project to everyone involved:

"R: I presented this way of working to them, to the mobile people. And they were really... oh this is nice and simple and easy to understand for everybody and very effective. In the end we had our on-line reports. People didn't even have to go into the system themselves any more, they could just.... Especially the project managers, the information they needed directly from the web with one click in these pre-defined tables."

(MT4-19-2:05b)

\section{Discussion}

The underlying tenet of the ICD approach is that issues concerning coordination, communication and shared meaning must be confronted head-on in order to manage DSD. Thus, the social aspects should frame the more technical ones, like writing a piece of software code or doing traditional resource and time planning of projects. In this section, we will discuss how some DSD challenges are addressed from this perspective.

\section{Architectural design}

When modelling the architecture of a complex system, a choice of perspective must be made. In the ICD approach, a functional perspective is taken. The anatomy shows the architecture of the telecom system in terms of dependencies between functions. Other aspects are suppressed, for example, the system structure (what parts the system consists of). There are mainly two reasons for this choice. The first one is the conviction that in order to manage complexity, you need to understand how things depend on each other. The other reason is that the anatomy provides a basis for the incremental integration of the system from basic functionality to an operational system. 
The architecture plays a key role in the coordination of DSD: "The coordination of multi-site work needs a common understanding of the architecture of the system to direct the development the work toward a coherent, working system" ([28], p. 245). Achieving common understanding is an intentional feature of the anatomy approach. The anatomy is usually drawn on a singe page that can be placed on a wall or put on a web page. It is defined in a process where key actors come together and work out the architecture of the system [23]. In this way, the anatomy provides one view of the system for all actors, regardless of how they are distributed across geographical and organizational borders. In other words, it provides a central coordinating mechanism of multi-site projects.

\section{Project Management}

When distributing the development task it is vital to consider group cohesion and task coupling [31]. Group cohesion refers to variations in language, culture, organization and countries. A group with large variety in these respects is defined as having low group cohesion. Task coupling refers to the need of co-presence, proximity and faceto-face communication.

The concepts of group cohesion and task coupling may be utilized when defining the increments in the ICD approach. The obvious choice is to define increments that delineate tasks with high group cohesion and high task coupling. For example, increments, which according to the anatomy have a large number of functional dependencies, should be avoided since this almost certainly leads to a high degree of task coupling. Another aspect is that the increment plan may be structured with respect to groups having a high degree of group cohesion.

In the ICD approach, the definition of the anatomy needs a lot of interaction, communication and face-to-face meetings among actors from various sites. Thus, anatomy definition is a task that has a high degree of task coupling and low group cohesion. By participating in this work, the actors will communicate the shared meaning of the anatomy at their home sites. In other words, they will act as liaisons in the project, something that have been identified as quite important in DSD [6].

Another important aspect of the ICD approach is that all its elements can be utilized in distributing the tasks. For example, the architecture of the system can be defined in such a way it alleviates the definition of tasks with high group cohesion and low coupling. This is of course only possible in situations where the architecture is not settled, for example when developing a new system.

Furthermore, the ICD approach enhances commitments and responsibilities. The increment and integration plans clearly signify which groups are responsible for what. Moreover, the dependencies between groups are evident. This is also amplified by the traffic light cues for signalling the progress of the project.

\section{Multiculturalism}

Multiculturalism in DSD implies both risks and possibilities. Strong group cohesion may be advantageous in developing a certain increment. On the other hand, multiculturalism may lead to misunderstandings and conflicts. Here, we shall discuss one aspect of multiculturalism: the balance between common and local ways of working.

There are different opinions about the role of commonality in DSD. For example, Ebert and De Neve from Alcatel recommend that all sites working with the same type of products should use common processes, methods and terminology [12]. On the 
other hand, Battin et al. from Motorola regard not imposing a common process as a key strategy in DSD [6]. Even though it is desirable to use the same tools, methods and processes throughout the project, this is seldom, if ever, an option. This is especially so if the DSD project is a more or less temporary configuration of otherwise independent organizations.

The distribution of local versus central control has been a recurrent issue at $\mathrm{Er}$ icsson. Decentralization driven too far has caused problems:

"We can state that the decentralization of... the method and process work that we have today, that our units within the Ericsson company have their own subsidiaries work very differently, that we work very differently within one and the same company. Even if we should know this after this many years so, instead of consolidating into a unified way of working, it has diverged into 40 different ways of working." (PM2, S-domain)

On the other hand, enforcing a common way of working is also problematic:

"I know there are some initiatives and try to come up with one object model for all projects within Ericsson. And I think that's a little bit trying to search for the Holy Graal. [...]. I mean you can even see how different the ways of working are within our subprojects at this moment because of the characteristics of the products and the areas where they are located and so on. To even keep one common way of working for that is really quite a challenge. So if you try to come up with one way of working in the projects within Ericsson, a common object model for that, I think that that's way too ambitious at the moment." (PM4, A-domain)

The ICD approach provides a framework managing these matters. The integration of increments can be coordinated without imposing a common way of working in each increment. Moreover, even if the Domain Construction Strategy assumes that coordination domains are constructed locally, some elements in each domain can be enforced in order to enable coordination between the domains. Examples of such elements are the work package definition, the identification rules for products and documents, the IS platform, etc. Thus, the effect of the ICD approach is that it problemizes the issue of balancing centralization versus decentralization in DSD.

\section{IS / IT support}

The result from the Ericsson practice underscores the importance of securing the capacity of the IT infrastructure and ISs before implementing the ICD in DSD projects. Moreover, issues of usability, user training and user support must be addressed.

In addition, the ICD approach requires a high degree of flexibility of the IS. During the construction of the coordination domain, the implementation of the context model needs to be frequently modified. This also applies to the long-term evolution of the domain. The flexibility requirement rules out most large, globally accessible IS, such as PDM and ERP (Enterprise Resource Planning) systems, as candidates for the ICD approach. In fact, to the best of our knowledge the Matrix PDM system from Matrix-One is so far the only IS fulfilling the flexibility requirement.

A main issue all throughout the deployment of the ICD approach was the role of Matrix in the overall IS architecture at Ericsson. IS architectures have been extensively discussed in the literature (e.g. [2], [4], [7], [10], [18], [30]). From the ICD point of view, the IS architecture must permit different IS implementations in each coordination domain. This can be achieved by using different IS platforms in each domain. Often, this is the only option available since a certain platform may be already in 
place. However, it is more advantageous if the IS platform can be the same in all coordination domains since this facilitates the interaction between the ISs. For example, information exchange of increment status in the $\mathrm{A}$ and $\mathrm{S}$ domains respectively would have been much easier if the two Matrix databases had been connected. Technically, this is quite possible, for example, through federated databases or an XML-based information exchange.

Another aspect of the IS architecture is related to the roles of different ISs in each domain respectively. In both the A and S domains, the intention was to manage as many types of coordination items as possible in Matrix. However, in most existing IS architectures this is not the case. Usually, there is one IS for each coordination area, i.e., one IS for requirement management, one for engineering change orders, one for test management, etc.

As can be seen from the results, the ability to manage all types of items in the same IS is very advantageous. Some reasons for this are:

- Interfaces between ISs in the coordination domain are not needed.

- The coordination information is consistent.

- There is a homogeneous worldview of the entire coordination domain.

- Changes, which are common to all coordination areas, are easier to implement.

- The ability to react to changes is higher.

There will still be a need to interface the coordination domain IS to other ISs. For example, the management of files for software development should be done by special purpose SW configuration management tools. However, such interfaces will be on the border of the coordination domain rather than inside it.

\section{Problems related to the ICD approach}

Besides the Ericsson specific problems already discussed there are some problems of a more general nature associated with the ICD approach. Defining the anatomy is often hard work. The actors may disagree about what to include in the anatomy and the level of detail in it. Sometimes there are also opposing views of how the system actually works. Moreover, the ICD approach enforces a new mind setting which is not accepted by all actors.

Some other problems might be:

- The IS in the ICD approach can in principle replace specialized management ISs supporting, for example, requirement management, engineering change order management, etc. However, actually carrying out such a replacement is problematic.

- The IS may not be compliant with corporate IS strategies. For example, the organization may have decided for an ERP system such as SAP to support multisite processes. Quite naturally, it is desirable to use this system in as many areas as possible. Even if a system as SAP would be very inadequate for the ICD approach due to low flexibility, it may be difficult to get acceptance for introducing yet another IS platform in the organization. 
- The Domain Construction Strategy presumes an iterative IS development method where the implementation is frequently changed. From a conventional engineering point of view, changes indicate a badly specified system. Thus, the ICD approach entails a new understanding of what characterizes good engineering practice.

- Currently, there are no established criteria for identifying an optimal set of coordination domains.

\subsection{The construction of shared meaning}

The difficulties in constructing shared meaning emanates from lack of objective criteria by which a "correct" model can be evaluated. Like Wittgenstein, we believe that the meaning of a phenomenon is determined in the social activity in which actors participate [36]. As long as a meaning of a word or sign brings about actions with intended consequences, the word is "correct". When misunderstandings or disagreements occur, the meaning of the word must be considered and reflected upon. This means that the only criteria by which "correctness" can be resolved is usability. For example, "WP" in Figure 11 signifies the phenomena "work package" in the Sdomain. However, outside Ericsson (and in fact outside the S-domain at that time) "work package" has other connotations.

Thus, disputes regarding meaning cannot ultimately be resolved around the table in a conference room. The context model and its associated IS implementation must gain their credibility on the combat field where projects are making use of them in their struggle to develop systems. If the context model is detached from the practice, it will rapidly turn into a reified phenomenon without practical relevance.

\subsection{Limitations}

The ICD approach has, to the best of our knowledge, been applied only in the Ericsson development practice. This raises questions about the transferability of the results to other DSD enterprises. As pointed out, the development of telecom systems can be seen as a paradigmatic area comprising most, if not all, of the challenges in DSD. However, this is an issue for further research.

Another issue concerns the IS used in the Domain Construction Strategy. Again, the experiences so far comes from one particular IS, the Matrix PDM system. It is desirable to identify general criteria by which other IS could be evaluated for use in the ICD approach.

In this paper we do no treat impacts from the SW development model on the ICD appraoch. Nor do we treat the SW configuration management of source code files during the writing of the SW. This is an important subject in itself which is treated extensively in the literature. For example, interfacing SW configuration management and engineering is discussed in [8].

\section{Conclusions}

We have presented the ICD approach of coordinating DSD tasks at Ericsson. The approach addresses many of the challenges inherent in DSD; above all those associated with social aspects such as communication, coordination and shared meaning construction. Although the approach so far is limited to one company, the results are 
encouraging. Extraordinary complex nodes in the $3^{\text {rd }}$ generation of mobile systems have been successfully developed subject to very demanding circumstances. Our main conclusion is that the ICD approach can be apprehended as a "bridgehead" into conquering new insights in managing distributed software development.

\section{References}

[1] N. Adler, Managing Complex Product Development - Three approaches, EFI, Stockholm School of Economics. ISBN: 91-7258-524-2, 1999.

[2] B.R. Allen, A.C. Boynton, Information Architecture: In Search of Efficient Flexibility, MIS Quarterly, December 1991, pp 435-445.

[3] J. Anderstedt, U. Anderstedt, M. Karlsson, M. Klasson M, Projekt och helhet - att leda projekt i praktiken, Författares Bokmaskin (in Swedish), Stockholm,2002, ISBN: 91-7910$380-4$.

[4] K. Axelsson, Metodisk systemstrukturering - att skapa samstämmighet mellan informationssystemarkitektur och verksamhet, Dissertation No. 1, Department of Computer and Information Science, Linköping University, Linköping (in Swedish), 1998.

[5] R. Baskerville, T. Wood-Harper, A Critical Perspective on Action Research as a Method for Information Systems Research, Journal of Information Technology 11, 1996, pp. 235-246.

[6] R. Battin, R. Crocker, J. Kreidler, K. Subramanian, Levering Resources in Global Software Development, IEEE Software, March / April, 2001, pp. 70-77.

[7] Broadbent M, Weill P (1997): Management by Maxim: How Business and IT Managers

Can Create IT Infrastructures, Sloan Management Review, Spring 1997, pp. 77 - 92.

[8] I. Crnkovic, U. Asklund, A. Persson Dahlqvist, Implementing and Integrating Product Data Management and Software Configuration Management, Artech House, London, 2003.

[9] D. Damian, Global Software Development: Growing Opportunities, Ongoing Challenges, Software Process Improvement and Practice, 8, 2003, pp. 179 - 182.

[10] M.J. Earl, An Organizational Approach to IS Strategy Making, in: M.J. Earl (Ed.), Information Management - The Organizational Dimension, Oxford University Press, 1996, pp. $136-170$.

[11]P. Ehn, Work-Oriented Design of Computer Artefacts, Arbetslivscentrum, Stockholm, Sweden, 1998.

[12]C. Ebert, P. De Neve, Surviving Global Software Development, IEEE Software, March / April, 2001, pp. $62-69$.

[13] S.D. Eppinger, D.E. Whitney, R.P. Smith, D.A. Gebala, A Model-Based Method for Organizing Tasks in Product Development, Research in Engineering Design, 6(1), 1994, pp. 113.

[14] M. Eriksson, J. Lilliesköld, N. Jonsson, D. Novosel, How to Manage Complex, Multinational R\&D Projects Successfully, Engineering Management Journal, Vol.14, No.2 June 2002, pp. 53-60.

[15] G. Goldkuhl, A. Röstlinger, Expanding the scope: From language action to generic practice, in Proceedings of the 4th International Workshop on the Language Action Perspective (LAP99), Copenhagen, 1999.

[16]R. Heeks, S. Krishna, B. Nicholson, S. Sahay, Synching or Sinking: Global Software Outsourcing Relationships, IEEE Software, March / April, 2001, pp. 54-60. 
[17] J. Herbsleb, D. Moitra, Global Software Development, IEEE Software, March / April, 2001, pp. 16-20.

[18] M.Å. Hugoson, Verksamhetsbaserad systemstrukturering, NordDATA90, Göteborg, pp. 267-274 (in Swedish), 1999.

[19]W.S. Humphrey, The software engineering process: definition and scope, ACM SIGSOFT Soft-ware Engineering Notes, Proceedings of the 4th international software process workshop on Representing and enacting the software process, Vol. 14, 4, pp. 82-83, 1998.

[20]E.A. Karlsson, L.G. Andersson, P. Leion, Daily build and feature development in large distributed projects, Proceedings of the International Conference on Software Engineering ICSE 2000, IEEE CS Press, Los Alamos, California, 2000, pp. 649-658.

[21]R. Kraut, L. Streeter, Coordination in Software Development, Communications of the ACM, Vol. 38, No. 3, 1995, pp. 69 -81.

[22] R. Larsson, Coordination of Action in Mergers and Acquisitions - Interpretative and Systems Approaches towards Synergy, Dissertation No. 10, Lund Studies in Economics and Management, The Institute of Economic Research, Lund University Press, 1990.

[23] J. Lilliesköld, L. Taxén, M. Klasson, Managing complex development projects - using the system anatomy, 2005, (in progress).

[24] T. Malone, K. Crowston ,The Interdisciplinary Study of Coordination, ACM Computing Services, Vol. 26, no 1, 1994, pp. 87-119.

[25] Matrix-One Inc: http://www.matrixone.com/index.html, (accessed Feb, 2005).

[26]I.R. McChesney, S. Gallagher, Communication and co-ordination practices in software engineering projects, Information and Software Technology, 46, 2004, pp. 473-489.

[27]U. Melin, Koordination och informationssystem i företag och nätverk, Linköping Studies in Information Science, Dissertation No. 6, Institutionen för datavetenskap, Linköpings universitet (in Swedish), 2002.

[28]P. Ovaska, M. Rossi, P. Marttiin, Architecture as a Coordination Tool in Multi-site Software Development, Software Process Improvement and Practice, 2003, 8, pp. 233-247.

[29] R. Prikladnicki, J.L.N. Audy, R. Evaristo, Global Software Development in Practice Lessons Learned, Software Process Improvement and Practice, 8, 2003, pp. 267-281.

[30]T. Reponen, Organizational information management strategies, Information Systems Journal, no. 4, 1994, pp. 27-4.

[31]S. Sakthivel S, Virtual workgroups in offshore system development, Information and Software Technology (in press).

[32]T.R. Schatzki, Introduction: Practice theory, in: T.R. Schatzki, K. Knorr Cetina, E. von Savigny (Eds.), The practice turn in contemporary theory, Routledge, London, 2001.

[33]L. Taxén, A Framework for the Coordination of Complex Systems' Development. Dissertation No. 800. Linköping University, Dep. of Computer \&Information Science, 2003. Available at http://www.ep.liu.se/diss/science technology/08/00/index.html (accessed Feb 2005).

[34]L. Taxén, Interactivity and contextuality in organizational semiosis, Proceedings of the $7^{\text {th }}$ International Workshop on Organisational Semiotics, OS 2004, Setúbal, Portugal, July 2004, pp. 97-111. 
[35]L. Taxén, J. Lilliesköld, Manifesting Shared Affordances in System Development - the System Anatomy, ALOIS $* 2005$, The $3^{\text {rd }}$ International Conference on Action in Language, Organisations and Information Systems, 15-16 March 2005, Limerick, Ireland .

[36]L. Wittgenstein, Philosophical investigations, Basil Blackwell, London, 1958.

[37] R.K. Yin, Case study research. Design and methods, Sage, London, 1989. 